\title{
Maternal Factors for Low Birth Weight and Preterm Birth At Tertiary Care Hospital
}

\author{
Neebha Ojha ${ }^{1}$ \\ 'Department of obstetrics and gynecology, Tribhuvan University Teaching Hospital, Maharajgunj, Kathmandu, Nepal.
}

\begin{abstract}
Introduction: Low birth weight and preterm birth are the major community health problems in developing countries. They are the major determinants of perinatal survival and infant morbidity and mortality. The aim of this study was to determine the proportion and the maternal risk factors for low birth weight and preterm birth among hospital deliveries in Tribhuvan University Teaching Hospital.
\end{abstract}

Methods: A cross sectional retrospective study was carried out in the Department of Obstetrics and Gynecology of TUTH. Maternal risk factors like age, parity, ethnicity, history of previous abortion, history of previous cesarean section, antepartum hemorrhage and medical disorders were studied. Information on all births that occurred was extracted from maternity case notes and delivery registers.

Results: During the study period, there were 685 singleton live births. Among these 78(11.4\%) were low birth weight and $47(6.9 \%)$ were preterm birth. The mean birth weight was $2950 \pm 488 \mathrm{gm}$. The mean weight of female was statistically less compared to male babies $(\mathrm{p}=0.032)$. The significant risk factors for LBW were primiparity (OR 2.12; 95\% CI 1.25-3.58), Indo-Aryan ethnicity (OR 1.97; $95 \% \mathrm{CI} 1.12-3.45$ ) and history of medical disorder (OR 3.08; 95\% CI 1.17-8.12). As for PTB antepartum hemorrhage (OR 8.63; 95\% CI 1.99-37.30) and history of medical disorder (OR 3.20; 95\%CI 1.04-9.89) were significant risk factors.

Conclusions: Parity, ethnicity, and medical disorders were the main risk factors for low birth weight. Antepartum hemorrhage and medical disorders were significant risk factors for preterm birth.

Keywords: low birth weight; preterm birth; risk factors.

\section{INTRODUCTION}

Weight at birth is a good indicator for the newborn's chances of survival, growth, long-term health and psychological development. ${ }^{1}$ Low birth weight (LBW) has been shown to stem from both intrauterine growth restriction and preterm births, while in developed countries it is mainly attributable to preterm birth. ${ }^{2}$ Low birth weight babies among hospital deliveries in Nepal showed the prevalence of $23.1 \% .^{3}$ Of the 20 million
LBW infants born in 2005, more than half were born in South Asia; representing a low birth weight rate of $29 \% .^{4}$ Data on the frequency and risk factors of LBW and preterm birth (PTB) are crucial for the design of maternal and child health programs, particularly in

Correspondence: Dr. Neebha Ojha, Department of obstetrics and gynecology, Tribhuvan University Teaching Hospital, Maharaiguni, Nepal. Email: neebha.ojha@gmail.com, Phone: +977-9841288300. 
developing countries. ${ }^{5}$

The aim of this study was to find out the proportion and the relationship of the maternal factors with LBW and PTB among hospital births in TU Teaching Hospital.

\section{METHODS}

This was a retrospective study carried out in the department of obstetrics and gynecology of TU Teaching Hospital. Information on all births that occurred from $16^{\text {th }}$ April, 2013 to $21^{\text {st }}$ June, 2013 during the study period was extracted from maternity case notes and delivery registers. All the cases meeting the inclusion criteria were retrieved and recorded according to the questionnaire. Inclusion criteria were singleton live birth and gestational age $\geq 28$ weeks. Still birth and babies with congenital anomaly were excluded. Gestational age was calculated from the last menstrual period as recorded in the delivery register. Babies with birth weight $<2500 \mathrm{gm}$ were taken as LBW and delivering before 37 weeks as preterm. The risk factors studied were maternal age, parity, ethnicity previous history of abortion, previous history cesarean section, antepartum hemorrhage and medical disorders. Regarding ethnicity, it was divided into Indo-Aryans: Brahmin, Chetri, Tharu, Rajbanshi, Darai, Kumal, Majhi and Tibeto-Burmans: Newar, Gurung, Magar, Rai, Limbu, Sherpa, Thakali, Tamang, Jirel, Thami.

After the data collection, it was entered in computer. Computer software Statistical package for the Social Sciences (SPSS) 15 was used for processing and analysis of the data. Descriptive analysis of the result was done through frequency analysis and crosstabulation to determine the percentage. Mean birth weight was compared by using t-test. To determine the relationship between low birth weight/preterm birth and risk factors chi-square test was applied. The odds ratio (OR) and corresponding 95\% confidence intervals (Cls) of the risk factors was estimated using a uni-variate analysis. $P$ value $<0.05$ was regarded as statistically significant. Permission to conduct the study was taken from the department head. Approval to conduct the study was taken from the Institutional Review Board, TU Institute of Medicine.

\section{RESULTS}

During the study period, there were 705 births $(\geq 28$ weeks). Of these 695 were live and 10 were still births. Among the 695 live births, ten cases were further excluded due to twins $(n=8)$ and congenital anomaly $(n=2)$. Total 685 live births were analyzed for the study (figure 1). Among 685 live births, 78 (11.4\%) were low birth weight and $47(6.9 \%)$ were preterm birth. Of the total cases, $316(46.1 \%)$ were females and 369
(53.9\%) were males. Among the females, the LBW was $42(13.3 \%)$ while among males it was only $36(9.8 \%)$. The overall mean birth weight was $2950 \pm 488 \mathrm{gm}$ and the mean birth weight of the female was statistically less compared to male (2907 vs $2987 \mathrm{gm} ; \mathrm{p}=0.032$ ). The LBW rate decreased as the gestational age increased. The mean birth weight was $1171 \pm 864 \mathrm{gm}$ at $28-33$ weeks while at term it was $2995 \pm 439 \mathrm{gm}$. The place of residence did not have any effect on the LBW and mean birth weight.

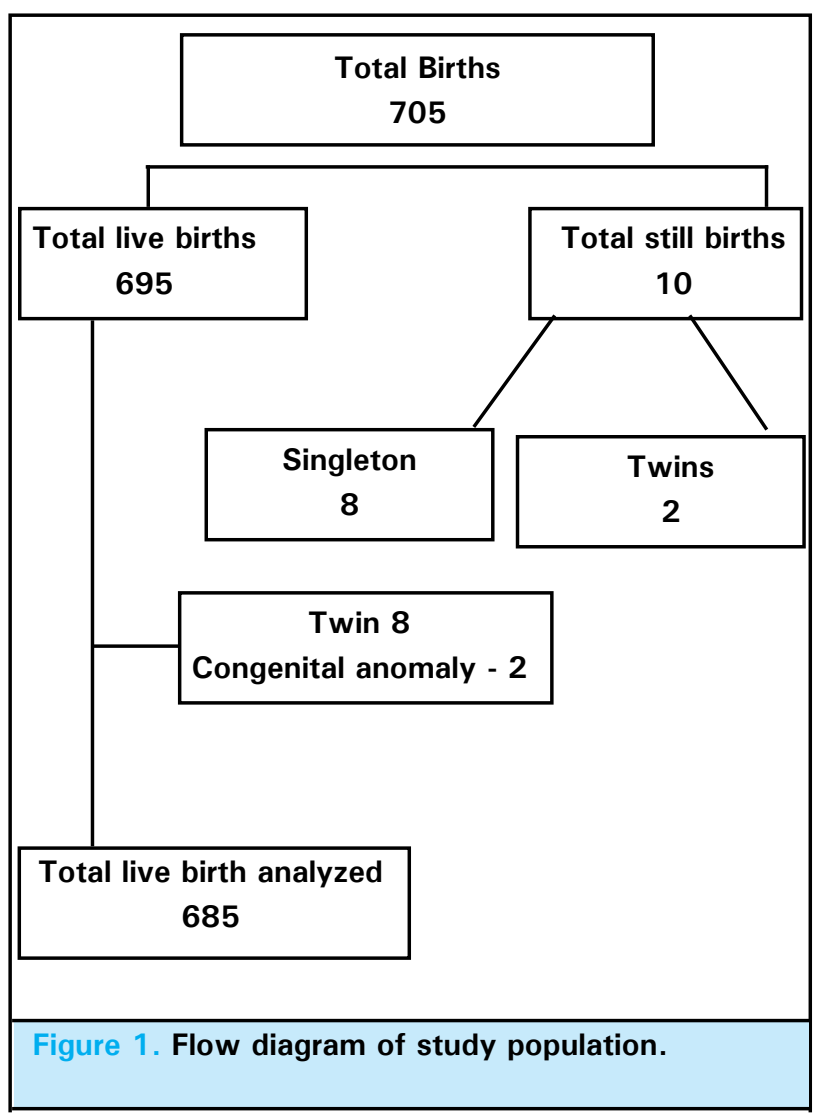

Maternal age ranged from 17 to 44 years. Most of women $521(76 \%)$ were in age group $20-29$ years. The mean birth weight of the babies increased with the increasing maternal age. Fifty eight percent $(n=398)$ of the women were primipara. Mean birth weight was higher among multi than in primipara. Sixty six percent $(n=453)$ of the women were Indo-Aryans, while one third were Tibeto-Burman. The mean birth of the babies was significantly more in Tibet-Burmans than among Indo-Aryans (2892 vs 3064 gm; $p=0.000$ ). Twenty three percent $(n=160)$ of the women had history of previous abortion and $7 \%(n=48)$ had history of cesarean section. Among forty two cases with medical disorders 20 cases had hypertensive disorders, 16 heart disease, 2 renal disorders, 3 hepatic disorders and one with myasthenia gravis. 
Table 1. Distribution of cases according to sex of baby, gestational age and residence.

\begin{tabular}{|lllll|}
\hline & Total birthN(\%) & LBWN(\%) & NBW(\%) & Mean BW SD(gm) \\
All & $685(100)$ & $78(11.4)$ & $607(88.6)$ & $2950 \pm 488$ \\
Fex of baby & & & \\
Male & $316(46.1)$ & $42(13.3)$ & $274(86.7)$ & $2907 \pm 470$ \\
Gestational age (wks) & $369(53.9)$ & $36(9.8)$ & $333(90.2)$ & $2987 \pm 501$ \\
$28-33$ & $13(1.9)$ & & & $1171 \pm 864$ \\
$34-36$ & $34(5.0)$ & $11(84.5)$ & $2(15.5)$ & $2561 \pm 424$ \\
$37-41$ & $631(92.1)$ & $15(44.1)$ & $19(55.9)$ & $2995 \pm 439$ \\
$\geq 42$ & $7(1.0)$ & $52(8.2)$ & $579(91.8)$ & $3064 \pm 179$ \\
Residence & & 0 & $7(100)$ & $2917 \pm 497$ \\
Outside Kathmandu & $94(13.8)$ & $11(11.7)$ & $83(88.3)$ & $2952 \pm 487$ \\
Kathmandu & $586(86.2)$ & $67(11.4)$ & $519(88.6)$ & \\
\hline
\end{tabular}

Table 3 shows the odds ratio of maternal risk factors for predicting the low birth weight. Younger women ( $\leq 19$ years) had 1.87 times more risk of having LBW babies in comparison to those 20 years or older but it was not statistically significant $(p=0.124)$. In relation to parity, primipara were two times more likely to deliver LBW babies than multipara $(p=0.004)$. Similarly ethnicity and medical disorders were other significant risk factors. Indo-Aryans had almost two times risk of LBW in comparison to Tibeto-Burmans (OR 1.97; $95 \% \mathrm{Cl} 1.12-3.45)$ and associated medical disorders had 3 times risk for LBW (OR 3.08; 95\% Cl 1.1678.12). History of previous abortion, history of previous cesarean section and antepartum hemorrhage did not show significance.

\begin{tabular}{|c|c|c|c|}
\hline Risk factors & $\begin{array}{l}N=685 \\
(\%)\end{array}$ & $\begin{array}{l}\text { Mean Birth } \\
\text { Weight (gm) }\end{array}$ & $\begin{array}{l}P \text { value } \\
\text { (t test) }\end{array}$ \\
\hline \multicolumn{4}{|l|}{$\begin{array}{l}\text { Maternal } \\
\text { age(years) }\end{array}$} \\
\hline$\leq 19$ & $43(6.3)$ & $\begin{array}{l}2818 \pm \\
538\end{array}$ & \\
\hline $20-29$ & $521(76.0)$ & $\begin{array}{l}2928 \pm \\
467\end{array}$ & \\
\hline$\geq 30$ & 121 (17.7) & $\begin{array}{l}3091 \pm \\
532\end{array}$ & \\
\hline \multicolumn{4}{|l|}{ Parity } \\
\hline 1 & $398(58.1)$ & $2876 \pm 491$ & \\
\hline $2-4$ & $283(41.3)$ & $3053 \pm 463$ & \\
\hline
\end{tabular}

\begin{tabular}{|c|c|c|c|}
\hline$\geq 4$ & $4(0.6)$ & $3037 \pm 666$ & \\
\hline \multicolumn{4}{|l|}{ Ethnicity } \\
\hline Indo-Aryans & $453(66.1)$ & $2892 \pm 472$ & $0.000^{*}$ \\
\hline Tibeto-Burmans & 232 (33.9) & $3064 \pm 500$ & \\
\hline \multicolumn{4}{|l|}{$\begin{array}{l}\mathrm{H} / \mathrm{O} \text { Previous } \\
\text { abortion }\end{array}$} \\
\hline Yes & $160(23.4)$ & $3034 \pm 498$ & $0.013 *$ \\
\hline No & $525(76.6)$ & $2924 \pm 483$ & \\
\hline \multicolumn{4}{|l|}{$\begin{array}{l}\text { H/O Previous } \\
\text { cesarean }\end{array}$} \\
\hline Yes & $48(7.0)$ & $3013 \pm 414$ & 0.354 \\
\hline No & 637 (93.0) & $2945 \pm 493$ & \\
\hline \multicolumn{4}{|l|}{$\begin{array}{l}\text { Antepartum } \\
\text { hge }\end{array}$} \\
\hline Yes & $8(1.2)$ & $2756 \pm 249$ & 0.258 \\
\hline No & 677 (98.8) & $2952 \pm 490$ & \\
\hline \multicolumn{4}{|l|}{$\begin{array}{l}\text { Medical } \\
\text { disorders }\end{array}$} \\
\hline Yes & $42(6.1)$ & $2768 \pm 438$ & 0.075 \\
\hline No & $663(93.9)$ & $2956 \pm 489$ & \\
\hline \multicolumn{4}{|l|}{${ }^{*}$ p value $<0.05$} \\
\hline \multicolumn{4}{|c|}{$\begin{array}{l}\text { Table 3. Odds ratio of risk factor for predicting Low } \\
\text { Birth Weight. }\end{array}$} \\
\hline Risk factors & \multicolumn{2}{|c|}{ OR (95\%Cl) } & $P$ value \\
\hline \multicolumn{4}{|c|}{ Maternal age(years) } \\
\hline$\leq 19$ & \multicolumn{2}{|c|}{$1.87(0.83-4.19)$} & 0.124 \\
\hline$>19$ & \multicolumn{2}{|l|}{1} & \\
\hline \multicolumn{3}{|l|}{ Parity } & \\
\hline
\end{tabular}




\begin{tabular}{|c|c|c|}
\hline Para 1 & $2.12(1.25-3.58)$ & $0.004 *$ \\
\hline$>1$ & 1 & \\
\hline \multicolumn{3}{|l|}{ Ethnicity } \\
\hline Indo-Aryans & $1.97(1.12-3.46)$ & $0.017^{*}$ \\
\hline Tibeto-Burmans & 1 & \\
\hline \multicolumn{3}{|l|}{$\begin{array}{l}\mathrm{H} / \mathrm{O} \text { previous } \\
\text { abortion }\end{array}$} \\
\hline Yes & $0.69(0.38-1.27)$ & 0.230 \\
\hline No & 1 & \\
\hline \multicolumn{3}{|l|}{$\begin{array}{l}\mathrm{H} / \mathrm{O} \text { previous } \\
\text { cesarean }\end{array}$} \\
\hline Yes & $0.89(0.34-2.35)$ & 0.826 \\
\hline No & 1 & \\
\hline \multicolumn{3}{|l|}{ Antepartum hge } \\
\hline Yes & $1.11(0.14-9.17)$ & 0.921 \\
\hline No & 1 & \\
\hline \multicolumn{3}{|l|}{ Medical disorders } \\
\hline Yes & $3.08(1.17-8.12)$ & $0.017^{*}$ \\
\hline No & 1 & \\
\hline
\end{tabular}

\begin{tabular}{|c|c|c|}
\hline Risk factors & OR(95\%Cl) & $P$ value \\
\hline \multicolumn{3}{|l|}{$\begin{array}{l}\text { Maternal } \\
\text { age(years) }\end{array}$} \\
\hline$\leq 19$ & $0.65(0.15-2.76)$ & 0.554 \\
\hline$>19$ & 1 & \\
\hline \multicolumn{3}{|l|}{ Parity } \\
\hline Para 1 & $1.17(0.64-2.16)$ & 0.604 \\
\hline$>1$ & 1 & \\
\hline \multicolumn{3}{|l|}{ Ethnicity } \\
\hline Indo-Aryans & $1.10(0.58-2.07)$ & 0.769 \\
\hline Tibeto-Burmans & 1 & \\
\hline \multicolumn{3}{|l|}{$\begin{array}{l}\mathrm{H} / \mathrm{O} \text { previous } \\
\text { abortion }\end{array}$} \\
\hline Yes & $0.76(0.36-1.16)$ & 0.480 \\
\hline No & 1 & \\
\hline \multicolumn{3}{|l|}{$\begin{array}{l}\mathrm{H} / \mathrm{O} \text { previous } \\
\text { cesarean }\end{array}$} \\
\hline Yes & $0.57(0.13-2.43)$ & 0.444 \\
\hline No & 1 & \\
\hline \multicolumn{3}{|l|}{ Antepartum hge } \\
\hline Yes & $8.63(1.99-37.30)$ & $0.001 *$ \\
\hline No & 1 & \\
\hline \multicolumn{3}{|l|}{ Medical disorders } \\
\hline Yes & $3.20(1.04-9.89)$ & $0.033^{*}$ \\
\hline No & 1 & \\
\hline
\end{tabular}

As for preterm birth as shown in Table 4 the significant risk factors were antepartum hemorrhage and medical disorders (OR 8.63 and 3.20 respectively).

\section{DISCUSSION}

In the present study the rate of low birth weight (LBW) was $11.4 \%$ and preterm birth weight was $6.9 \%$ among 685 singleton live births. Different studies from Nepal have shown the prevalence of LBW ranging from 20 to $30 \%$. $^{3,6,7}$ Similar prevalence is found in India Karnataka $(22.9 \%)$ in rural community based study. ${ }^{8}$ The prevalence in these studies are high in comparison to present study as they are done on rural part of the country and being community based study. A hospital based study done in Kavre Nepal has shown incidence of LBW $11.07 \%$, which is similar to the present study. ${ }^{9}$ A hospital based study done in Maternity Hospital, the incidence of term low birth weight was $12.76 \% .^{10}$ Another hospital based study done in India has shown a low prevalence rate of $6.16 \%$ among 650 singleton deliveries. ${ }^{11}$ Regarding preterm birth, it was $6.9 \%$ of the total birth in this study. The prevalence of preterm birth was $15.7 \%$ in Nepal, $10.9 \%$ in a study done in Gambia and $9.97 \%$ in India. ${ }^{3,12,13}$ The prevalence preterm birth is lower in this study in comparison to the previous studies which may be due to the lower rate of LBW itself. In the present study, among the LBW babies most of them were contributed by preterm constituting $91.8 \%$ and only $8.2 \%$ were term. Other studies have shown similar results, where preterm LBW birth contributed $80-94 \%$ of total LBW. ${ }^{12,13}$ Older studies have shown preterm birth contributed only $30-46 \%$ of LBW. ${ }^{6,14}$ In the present study, the mean birth weight was $2950 \pm 488 \mathrm{gm}$. Various studies have shown similar results as $2750 \pm 639 \mathrm{gm}$ by Yadav et al, $3013 \mathrm{gm} \pm 541 \mathrm{gm}$ by Jammeh et al and $2592 \pm 371 \mathrm{gm}$ by Bisai et al. ${ }^{7,12,13}$

Among the 685 births, 369 (53.9\%) of the births were male and rest females. Among females $42(13.3 \%)$ were LBW while among males only $36(9.8 \%)$. Similar to this study, male LBW was $9.2 \%$ while in females it was $12 \%$ in study done in Gambia. ${ }^{12}$ Several studies have shown the mean birth weight of the male babies to be more than that of the females. ${ }^{7,12,13}$

Among the different risk factors, primi parity, IndoAryan ethnic group and medical disorders were the significant risk factors for the LBW. Present study showed primi para women have two times risk of having LBW babies in comparison to multipara (OR 2.117: $95 \% \mathrm{Cl} 1.25-3.58)$. In a study done in kolkata among 331 mother-baby pair primi para women were at significant risk of LBW in comparison to multipara (OR $2.45 ; 95 \% \mathrm{Cl}$ 1.48-4.06). ${ }^{13}$ Many studies have shown younger age to be a risk factor for LBW.7,13,15,16 A study 
done in Gambia reported younger mothers $<20$ years and primiparous mothers respectively, were 1.8 and 2.5 times more likely to deliver a LBW baby than older mothers who were $\geq 30$ years old and the multiparous with $\geq 5$ deliveries. ${ }^{12}$ However in this study younger women $<19$ years had 1.8 times more risk for LBW but it was not significant.

Regarding ethnicity Indo-Aryans women were almost two times more at risk of having LBW babies in comparison to Tibeto-Burmans (OR 1.97; $95 \% \mathrm{Cl} 1.12$ 3.45). Ethnic background may have effect on the birth weight of the baby due to genetic growth potential and environmental factor such as food habits and cultural factors. Medical disorders was an important risk factor for LBW (OR $3.08 ; 95 \% \mathrm{Cl} 1.17-8.12$ ) in this study. Obstetric complications have a strong influence on birth weight as it affects the utero placental supply to the fetus leading to intrauterine growth restriction. Antepartum haemorrhage and hypertensive disorders in pregnancy were significantly associated with LBW (Crude ORs $=5.02$ and 2.86 ) respectively in a study in Gambia. ${ }^{12}$ Similar result was seen in another study in India. ${ }^{8}$
The significant risk factors for the preterm births were antepartum hemorrhage and medical disorders. This could be due to both spontaneous labor and iatrogenic due to premature termination of pregnancy for maternal or fetal indications. Others study have shown antepartum hemorrhage (OR 6.5), primiparity (OR 2.7) and hypertensive pregnancy disorders (OR 2.6) as significant risk factors. ${ }^{12}$ Prematurity itself is an important cause for LBW. Renzo et al had shown previous history of abortion and cesarean section as significant risk factor or PTB which is contrary to this study. ${ }^{17}$ This study had taken all cases of preterm birth while he has involved only cases of spontaneous labor.

\section{CONCLUSIONS}

Low birth weight is an important risk factor for perinatal morbidity and mortality in developing countries. As Primipara women and Indo-Aryan ethnic group are at higher risk for low birth weight babies, they should be provided preventive measures for LBW. As for preterm birth antepartum hemorrhage and medical disorders are to be managed or referred to higher centers for delivery as these are the high risk women and babies needing high dependency units for prematurity and its associated problems.

\section{REFERENCES}

1. WHO, UNICEF (2004) Low birth weight, country, regional and global estimates. WHO, Dept. of Reproductive Health Research, ISBN: 92-806-3832-7, New York, 1-32.

2. Kramer, MS. Determinants of low birth weight: Methodological assessment and metaanalysis. Bull World Health Organ 1987;65:663-737.

3. Koirala AK, Bhatta DN. Low birth weight babies among hospital deliveries in Nepal. A hospital based study. Internal Journal of Women's Health 2015;7:581-85

4. Feresu, SA., Harlow, SD., Welch, K. and Gillespie, BW. Incidence of and socio-demographic risk factors for stillbirth, preterm birth and low birth weight among Zimbabwean women. Paediatr Perinat Epidemiol2004;18:154-163.

5. UNICEF. (2006) The State of the World's Children 2007. The United Nations Children's Fund, UNICEF, New York, 2006.

6. MIRA/UNICEF Nepal (2000) Low Birth Weight Prevalence and Associated Factors in Four Regions of Nepal. Kathmandu, Nepal: Mother Infant Research Activities (MIRA), UNICEF.

7. Yadav DK, Chaudhary U, Shrestha. Risk Factors Associated with Low Birth Weight. JNHRC 2011;9(19):159-64.

8. Metgud CS, Naik VA, Mallapur MD. Factors Affecting Birth Weight of a Newborn -A Community Based Study in Rural Karnataka, India. [online] 2012 july 5. Available from: Journal plos.org/Plos one/Doi10.137/Journal pone .0040040.
9. Singh SD, Shrestha S, Marahatta SB. Incidence and risk factors of low birth weight babies born in Dhulikhel Hospital. JIOM 2010;32(3):39-42.

10. Ojha N, Malla DS. Low Birth Weight at Term: Relationship with Maternal Anthropometry. JNMA 2007;46(2):52-6.

11. Singh G, Chauhan R, Sidhu K. Maternal Factors for Low Birth Weight Babies. MJAFI 2009;65(1):10-12.

12. Jammeh A, Sundby J, Vangen S. Maternal and obsstetric risk factors for low birth weight and pretrem birth in rural Gambia: a hospital-based study of 1579 deliveries. Open Journal of Obstetrics and Gynecology 2011, 1, 94-103. [online] 2011 september doi:10.4236/ojog.2011.13017 Pu

13. Bisai S, Sen A, Mahalanabis D, Dutta N,Bose K. The effect of maternal age and parity on birth weight among Bangalees of Kolkata, India. Human Ecology special Issue 2006;14:139-143.

14. Khan N, Jamal M. Maternal risk factors associated with low birth weight. J coll Physicians surg Pak 2003;13(1):25-8.

15. Nair NS, Rao RS, Chandrashekar S, Acharya D, Bhat HV. Socio-demographic and maternal determinants of low birth weight: a multivariate approach. Indian J Pediatr. 2000;67(1):9-14. 
16. Sharma SR, Giri S, Timalsina U, Bhandari SS, Basyal B, Wagle K,Shrestha L. Low Birth Weight at Term and Its Determinants in a Tertiary Hospital of Nepal: A Case-Control Study. [online] 2015 April 8. Available from:Journal plos.org/Plos one | DOI:10.1371/journal.pone.0123962
17. Renzo GCD, Giardina I, Rosati A, Clerici G, Torricelli M, Petraglia F. Maternal risk factors for preterm birth: a country-based population analysis. European Journal of Obstetrics \& Gynecology and Reproductive Biology 2011;159(2):342-46. 